\title{
A STUDY OF THE TRANSLUCENCY OF THE STOMACH WALL WITH SPECIAL REFERENCE TO THE INFLUENCE OF THE GASTRIC MOVEMENT
}

\author{
YOSHIE KAJIMOTO AND SHIGENORI TAKUBO \\ Department of Pharmacology, Takushima University School of Medicine, Tokushima \\ SHUHEI TAKITA \\ First Department of Surgery, Tokushima University School of Medicine, Tokushima \\ Received for publication July 3, 1957
}

Changes in the motor or functional activity of the gastro-intestinal tract are believed by some to induce a significant change in the distribution of the blood in the body, which, according to Yokota (1), results in the alternation of the portal, and consequently of systemic blood pressure $(2,3)$. Machida and Yamamoto $(4,5)$ also point out a close relation between the motor activity and the circulation of the intestine. Ueda (6) raised an objection to this view, however, by emphasizing the importance of the individual responses of the musculatures of the vcssels and of the intestinal tract to drugs.

Few works have been reported on the circulation of the stomach except those of Debreff (7), Minamidani (8) and Carlson (9). Our previous papers (10-13) dealt with the changes in the blood volume in the stomach wall in response to the drugs or physical stimuli. Thesc experiments have been carried out with an aid of a photo-elcctric device, based on the principle that the translucency of the stomach wall should be affected by the amount of the blood present within the wall of the stomach. The work to be described in this paper was designed to solve a question that the gastric movement may modify the translucency to such an extent that the experimental results are mistakenly interpreted. The present investigation, accordingly, is directed to determine the extent of the influence of the gastric movements on the translucency of the stomach wall, and its relation to the results of previous experiment $(10,12,15)$.

\section{EXPERIMENTAL MATERIALS AND METHODS}

1) Adult dogs weighing about $10 \mathrm{~kg}$ were used. The animals were ancsthetized with $1.5 \mathrm{~g} / \mathrm{kg}$ of urethane. After a midline incision, the stomach was cxposed and a midget lamp was inserted through an incised small wound made on the pylorus wall and fixed to the stomach mucosa. A photo-electric tube was then placed on the serous coat, without undue pressure, so that the light-beam passing through the gastric wall reached the tube to be converted into electric current. Changes in the intensity of the light, therefore, can be amplified and registerd on the kymograph with an aid of an clectromagnetic lever. This tracing was, for the sake of brevity, designatcd as the translucency curve. For the recording of the intragastric pressure, an inflated balloon was introduced from the mouth into the stomach. 
Simultaneously, a serrefine was attached to the pylorus coat to record the movement of the pylorus. All these three tracings werc registered on the same kymograph (Fig. 1).

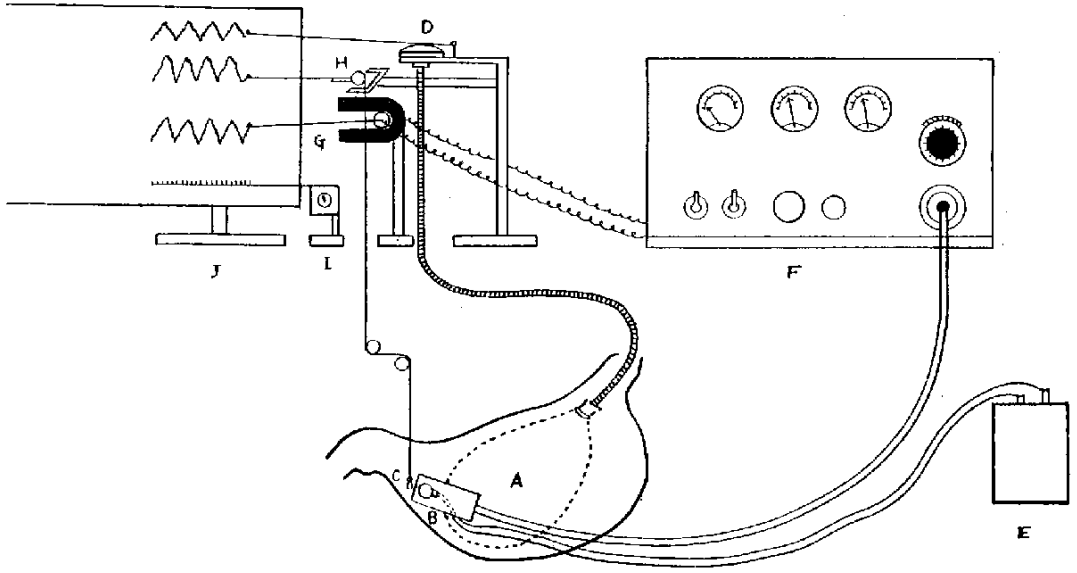

FIG. 1. Schematic illustration of the experimental method.

A: balloon, B : light-source and photo-electric tube, $\mathrm{C}$ : serrefine, D: tambour, E: battery $(1.5 \mathrm{~V}), \quad \mathrm{F}$ : amplifier, G: electromagnetic lever, H: lever, I : time marker, J : drum

2) Perfusion through the vascular bed of the stomach

To eliminate the effect of circulating blood on the translucency of the stomach wall, the stomach was perfused with Ringer-Locke's solution and the pure effect of the gastric contractions was registered.

Technical procedures: Adult dogs ancsthetized with $4 \mathrm{mg} / \mathrm{kg}$ of morphine plus $1 \mathrm{~g} / \mathrm{kg}$ of urcthane were used. Following a wide exposure of the stomach and its vicinity, the celiac artery was frecd from the surrounding tissues carefully, and tied off near the portion branching off from the aorta. An arterial cannula was then inserted into the celiac artery and ligated securely. 'The pancreatico-duodenal artery was also ticd off near the head of the pancreas. A small branch of the proper hepatic artery ascending to the hilus of the liver was also ligated.

A venous trunk consisting of the splenic vein and the left gastric vein was ligated just before it joins the mesenteric trunk. A venous cannula was inserted into the venous trunk and fixed in the same manner as with the artery. Small venous branches were all tied off.

Another small cannula was also inserted into the right gastric artery on some occasions to facilitate the perfusion (Fig. 2).

The stomach wall was perfused with Ringer-Locke's solution kept at 38 to $39^{\circ} \mathrm{C}$ employing the Langendorff's apparatus. The perfusion was made at a constant pressure of approximately $100 \mathrm{~mm} \mathrm{Hg}$, which had been determined by the prcliminary measurement of the ccliac arterial pressure (Fig. 3). For a more confirming evidence the perfusing RingerLocke's solution was replaced once again with the citrated blood and the resultant change in the translucency of the stomach wall was evaluated. The citrated blood was prepared in 


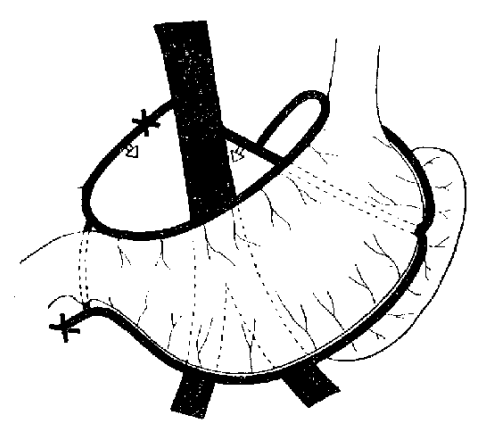

venous system

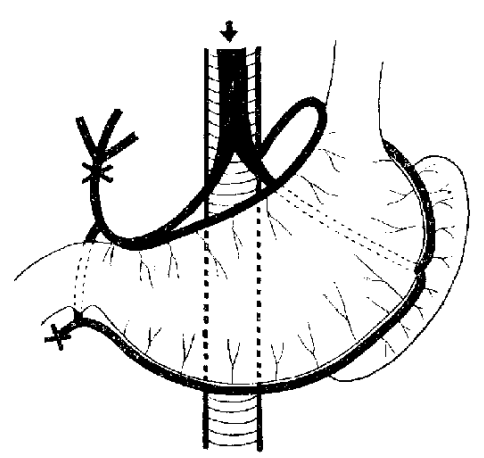

arterial system

FIG. 2. Schematic presentation of the vascular system of dog's stomach.

$\downarrow$ intraarterial cannula, $\sqrt{ }$ intravenous cannula, $x$ sites of ligature

the following way. About 40 c.c. of the blood was withdrawn from another $\operatorname{dog}$ and immediately mixcd with 10 c.c. of a $3.8 \%$ isotonic sodium citrate solution. The stomach was allowed to be perfused for the first 10 to 15 minutes to wash away the remaining blood completely. The administration of the drug was made by injecting in solution through the rubber tube connected to the arterial cannula after the outflowing perfusion fluid has become completely free from the bloody stain, and flows out as a constant ratc. The room tcmperature was kept at 25 to $28 \mathrm{C}$ throughout the experiment. Care was also taken to protect the abdominal viscera from cooling and drying. The upward movement in the translucency curve represents an increase in the translucency of the stomach wall, which in the perfused stomach should imply the

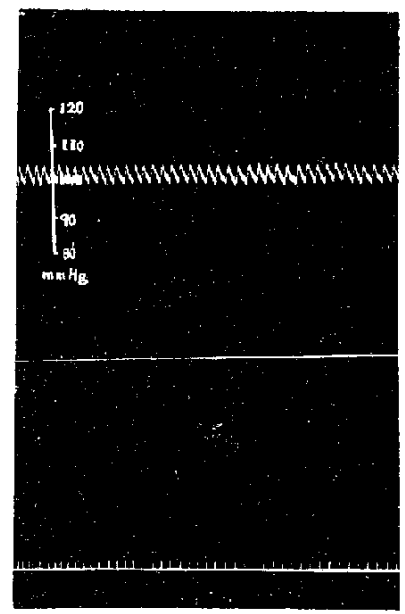

FIG. 3. Intraarterial pressure of dog's celiac artery.

Time signal 6 seconds alternation in the "thickness" of the wall owing to the gastric movements. In the stomach with physiological blood supply, however, it has been considered to represent the increase in the blood volume present in the stomach wall.

\section{RESULTS}

A. Relation between the gastric movement and the translucency of the gastric wall during fhysiological movement of the stomach

1) As shown in Fig. 4 and Fig. 5, the tracings of the translucency and gastric movements show the rhythmical fluctuations with the period of eighteen seconds (Table 1). The phase of contractions is associated always with the diminished translucency of the stomach wall and vice versa. 
TABLE 1. Comparison of the contraction period of the stomach with fluctuation period of the translucency curve.

\begin{tabular}{l|ccccccccc}
\hline \multicolumn{1}{c|}{ Number } & 1 & 2 & 3 & 4 & 5 & 6 & 7 & 8 & 9 \\
$\begin{array}{l}\text { Period } \\
\text { (in second) }\end{array}$ & 19 & & & & & & & & \\
\hline $\begin{array}{l}\text { Gastric } \\
\text { contraction }\end{array}$ & 19.2 & 26.4 & 16.8 & 18 & 18 & 19.5 & 15.6 & 19.2 & 16.8 \\
$\begin{array}{l}\text { Fluctuation of } \\
\text { transluccncy }\end{array}$ & 19.2 & 26.4 & 15.6 & 18 & 20 & 19.5 & 15.6 & 19.2 & 16.2 \\
\hline
\end{tabular}

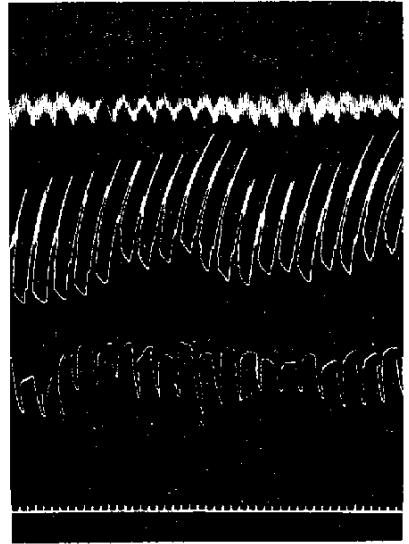

FIG. 4. Typical rhythmic contractions of the pyloric portion of dog's stomach. Time marks by 6 seconds

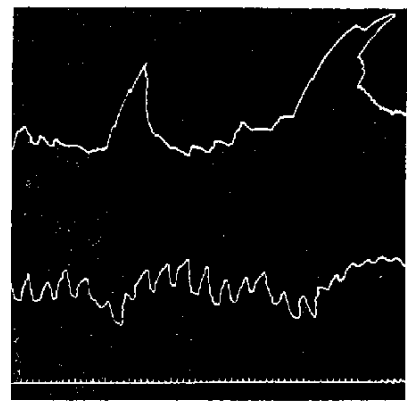

FIG. 5. Gross movement of Takita (see text).

2) In correspondence to the large wave of the stomach, i.e. "beträchtliche Tonusschwankung mit der gleichzeitigen Schwankung in der peristaltischen Stärke (14)," the rhythmic fluctuations on the mechanogram disappeared, and the translucency of the stomach wall diminished. The original rhylhmical fuctuations of the transluccncy were restored with the recovery of the peristaltic movement of the stomach (Fig. 5).

Takubo (15) and his coworker have shown in rabbit's stomach with normal blood sup-

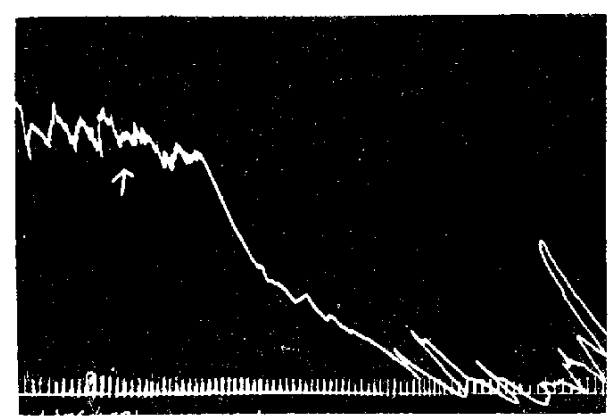

FIG. 6. Effect of $0.1 \mathrm{mg} / \mathrm{kg}$ of pilocarpine on the translucancy of the stomach wall (cited from Shikoku Acta Medica 5, 1). ply that the administration of pilocarpine resulted in the diminution of the translucency of the stomach wall, the rhythmic fluctuations in the translucency tracing becoming obscure but in due course of time the original fluctuations made their appearance once again to restore the rhythmic fluctuations (Fig. 6).

13. Effect of drugs on the transluency and the movement of the siomach

1) Adrenaline $(1 \mathrm{mg})$

No visible effects were observed except 
an occasional slight increase or decrease of the gastric movement. In the translucency curve, occasional fine and irregular fluctuations were recorded following the administration of adrenaline but, in general, no significant changes were demonstrated (Fig. 7).

In the stomach with physiological blood supply, however, adrenaline was found to cause a transient or prolonged incrcase in the

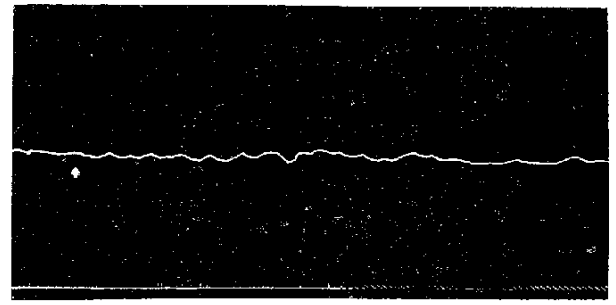

FIG. 7. Effect of $1 \mathrm{mg}$ of adrenaline on the translucency of the stomach wall. translucency of the stomach wall $(12,13)$, which seems to suggest the possible vasoconstricting effect of adrenaline on the blood vessels in the stomach wall.

2) Pilocarpine $(0.1 \mathrm{mg})$

The motor activity of the stomach was augmented considerably. The tracing of the translucency moved downward slightly (Fig. 8).

In the stomach with normal blood circulation $(10,12,13,15)$, pilocarpine elicited a rapid and marked decrease in the transluccncy.

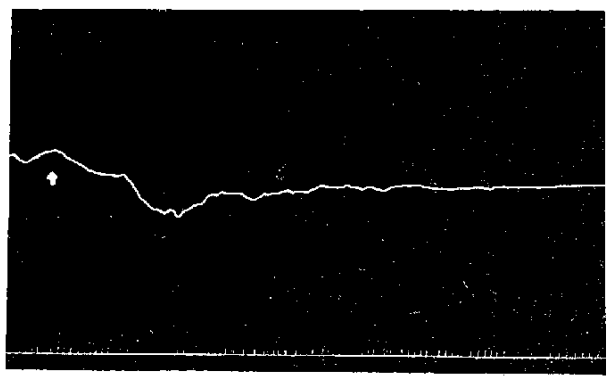

FIG. 8. Effect of $0.1 \mathrm{mg}$ of pilocarpine on the translucency of the stomach wall.

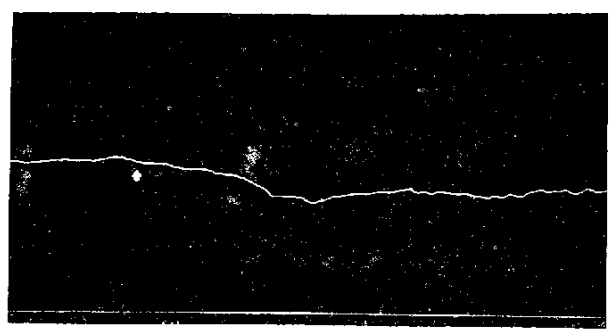

FIG. 9. Effect of $16 \mathrm{mg}$ of acetylcholine on the translucency of the stomach wall.

3) Acetylcholine $(10 \mathrm{mg})$

Gradual increase in the gastric activity followed the administration of acetylcholine associated with the decrease in the translucency of the stomach wall (Fig. 9).

In the stomach with physiological blood supply (10), the effect of acetylcholine was approximatcly the same as in the case of administering pilocarpine with a marked decrease in the translucency.

4) Benzyl imidazoline (BI) (20 mg)

Vigorous pcristaltic activity resulted from the administration of BI. The translucency of the wall diminished and the gastric activity was augmented (Fig. 10). In the stomach with normal blood supply $(10,12)$, BI caused a marked diminution of the translucency.

5) Tetrathylammonium bromide (TEAB) (200 mg)

No effect or slight inhibitory effect was demonstrated in the gastric activity by direct inspection. The translucency remained following the administration of TEAB (Fig. 11). 


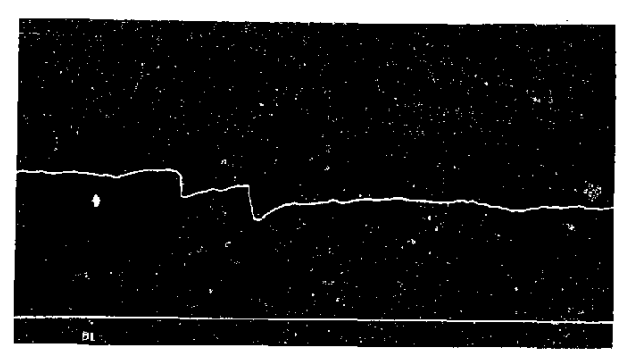

FIG. 10. Effect of $20 \mathrm{mg}$ of $\mathrm{BI}$ on the translucency of the stomach wall.

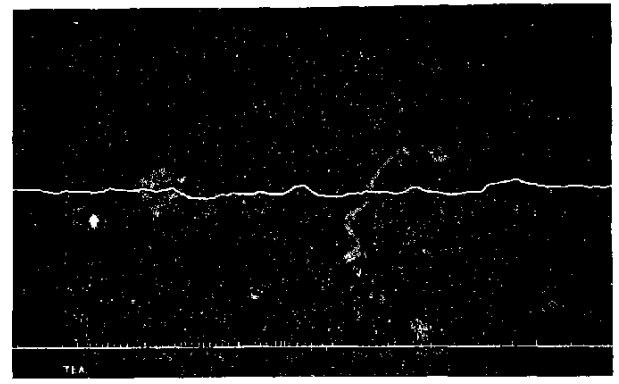

Fig. 11. Eflect of $200 \mathrm{mg}$ of TEAB on the translucency of the stomach wall.

The transluccncy of the stomach wall with normal blood supply (12) decreased immediatcly following the administration of TEAB.

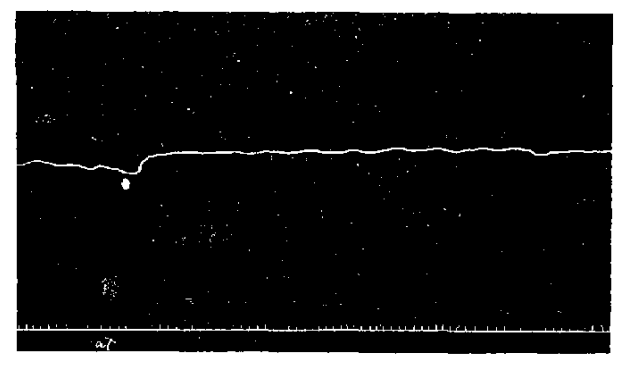

FIG. 12. Effect of $10 \mathrm{mg}$ of atropine on the translucency of the stomach wall.

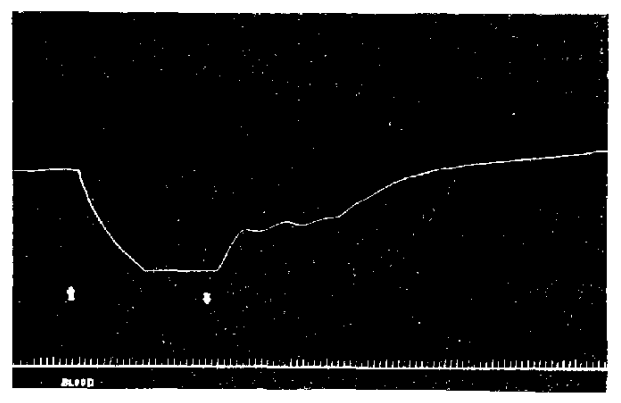

FIG. 13. Pcrfusing Ringer-Locke's solution was replaced by citrated blood during the period indicated by two arrow marks.
6) Atropine $(10 \mathrm{mg})$

The gastric motility was slightly depressed by $10 \mathrm{mg}$ of atropine. The translucency of the stomach was slightly increased (Fig. 12). In the stomach with normal blood supply (12), evident increase in the translucency was demonstrated. These results seems to indicate the diminished blood volume in the stomach wall.

7) Perfusion with citrated blood replacing the Ringer-Locke's solution

Immediately following the onset of the perfusion with the citrated blood replacing the Ringer-Locke's solution, the translucency of the stomach wall began to diminish abruptly (Fig. 13). The significant role of the circulating blood in the alternation of the translucency was reconfirmed by the replacement of the citrated blood once again with Ringer-Locke's solution which brought back the translucency to the original level.

\section{DISCUSSION AND SUMMARY}

Our previous studics on the blood volume change within the stomach wall have becn carried out by detcrmining the intensity of the translucent light-beam through the stomach wall.

The possible effect of the peristaltic movement or the tonus fluctuations on the translucency of the stomach wall was carefully investigated in the present experiment. Takita holds 
the view that the so-called twenty-second rhythm of the gastric movements in man represents the changes of the intragastric pressure by peristaltic waves, which is sometimes conspicuously modified by tonus state. More powerful changes of the intragastric pressure, i.c. the Carlson's (9) thirty-second rhythm, have their origin in the tonus fluctuations and has been designated as "large wave" by Takita.

Changes in the translucency by drug administrations or physical stimulation did not abolish the fine rhythmical fluctuations.

The influence of the tonus fluctuations on the translucency of the gastric wall was further observed by perfusing the vascular bed of the stomach with Ringer-Locke's solution.

The translucency curve of the perfused stomach wall shows almost not visible rhythmical fluctuations, but the peristaltic waves were found to make their appearance somewhere along the gastric wall by direct inspection.

In the tracings of the gastric movement and the translucency of the stomach wall, the rhythmical fluctuations at an interval of about eighteen-seconds were obviously seen.

It is evident from thesc results that the peristaltic waves, which periodically alternate the "thickness" of the gastric wall are reasonably considered to be responsible for the fine rhythmical fluctuations of the translucency curve.

In the stomach being perfused, the administration of $\mathrm{BI}, \mathrm{ACh}$, pilocarpine and other drugs acting to augment the gastric motility, however, caused a slight decrease in the translucency.

Pilocarpine has long been known to cause the contractions and augmented tone of the smooth muscle by its characteristic parasympathomimetic action (16-21). The smooth muscle of vessels, however, is believed not to be acted upon by pilocarpine. The peristaltic activity of the gastro-intestinal tract is also augmented.

Brodic and Dixon (22) stated that pilocarpine may act on the smooth muscle of the vascular beds innervated by the splanchnic nerves, whereas Bachr and Pick (23), Hunt (24), and Burn (25) agce in their findings that pilocarpine dilates the vascular vessel. According to Miyake (26) the mesenteric artery and vein dilate in response to the administration of pilocarpine.

In addition to increasing the tone and motility of the gastric muscle (27-29), ACh is considercd to have potent vasodilating action on almost all organs, though it is believed to be a little weaker in the vessels innervated by the splanchnic nerves (30), BI is gencrally known to block the autonomic ganglions and increase the gastric motility. Besides, BI exerts a vasodilating action dircctly on the vessels $(31,32)$.

It is cvident that these three drugs increase the gastric motility and cause the diminution in the translucency of the gastric wall in the stomach being perfused with Ringer-Locke's solution. But the extent to which the translucency is affected by the drugs is far greater in the stomach with normal blood supply than in the perfused stomach. This implies that changes of circulating blood volume have dominant effects on the translucency of the stomach wall.

Carlson (9) stated that the marked hyperemia of the gastric mucosa associated with powerful contractions of the stomach may either be due to the vascular dilation or to the 
mechanical obstruction of the venous outflow. The action of adrenaline on the gastric movements is highly controversial. Elliott (33) and Klee (34) claimed that the action of adrenaline is inhibitory on the alimentary tract. Watanabe (35) reported the initial excitatory action which was followed by the decrease of the muscular tone and peristaltic activity. Akasome (36) and Kataki (37) describcd the pure stimulating action of adrenaline on the stomach activity. Adrenalinc has a vasoconstricting action on organs innervated by the splanchnic nerve, particularly in the kidneys and on vessels in the mucous membrane. Differences in the effects of adrenaline on the stomach wall translucency with normal blood supply and with perfusion indicates the possible constricting effect of adrenaline on the blood vessels. Atropine is believed to act on the central nervous system and also on effector organs innervated by postganglionic cholinergic nerves. The motor effect on the stomach (38) is generally inhibitory (39-41). It is agreed that atropinc has no characteristic effect on the blood vessels by itself. The effect of atropine on the translucency of the gastric wall was more conspicuous in the stomach with normal blood supply than in the stomach being perfused with saline. The significance of this important discrepancy may be explained on the basis of the assumption that in addition to the inhibitory effect of the gastric motility, atropine exerts a vasoconstricting action on the blood vessels within the stomach wall.

The tone and motility of the stomach are decreased by TEAB $(42,43)$. No appreciable change occurred in the translucency of the perfused stomach, where a transient or prolonged decrcase in the translucency was observed in the stomach with physiological blood supply.

The effect of pilocarpine, ACh, atropine and adrenaline on the gastric motility and the circulation are similar to the results of the experiments performed on the intestine by Machida and Yamamoto (4), and Ueta (6), namcly; the blood flow increased associated with augmented gastric motility and decreased in association with decreased movement. The replacement of perfusing solution with citrated blood or vice zersa, resulted in a marked change in the transluccncy of the stomach wall.

In summarizing these experimental results and observations, it is clear that fine rhythmical fluctuations of the translucency curve indicatc peristaltic waves of the stomach wall associated with the tonus fluctuations of the gastric musculature.

In response to drug administrations or physical stimuli, the transluccncy curve moves either downward or upward with the fine rhythmical fluctuations present on the tracing. These up- or downward movements of the transluccncy curve may be understood as the integrated expression of the effects of the drugs or physical stimuli on the muscular tone of the gastric wall and on the vascular vessels in the stomach wall which consequently affect the translucency of the stomach wall.

\section{CONCLUSION}

In the dog's stomach with normal blood supply, peristaltic waves make their appearance at an interval of about 18 seconds. The translucency of the stomach wall fluctuates in correspondence to the appearance of the peristaltic waves, 
The translucency of the wall diminishes in association with peristaltic contraction and increases during the relaxation phase.

The gross movement associated with powerful tonus fluctuation gives rise to a marked diminution of the translucency.

In the stomach being perfused with Ringer-Locke's solution, the administration of pilocarpine, ACh and BI results in the slight decrease in the translucency.

Administration of atropine causes a slight increase in the translucency. No appreciable changes were induced by the administrations of TEAB and adrenaline. It was also shown that the translucency of the perfused stomach wall where the effect of the circulating blood on the translucency has been eliminated, decreases slightly corresponding to the phase of augmented muscular tone of the stomach wall and increases during the phase of motor relaxation.

In addition to the effect of motor activity of the stomach on the translucency of its wall, the volume of the circulating blood in the vascular bed of the stomach wall is considered to play an important role in the alternation of the translucency. The interpretation of the translucency curve, therefore, calls for a carcful consideration as to these two factors discussed in this paper.

\section{REFERENCES}

1) Yokota, K.: Medicine 6, 448 (1949) (Japanese)

2) OKaE, H.: J. of Kyoto Prefectural Med. Coll. 13, 605 (1935)

3) RYONO, E. : Ibid. 57, 397 (1955)

4) MACHIDA, M. AND YAMAMOTO, A.: Ibid. 6, 1043 (1932)

5) NamikawA, T.: Ibid. 11, 199 (1934)

6) UETA, I.: Igaku-kenkyu 21, 71 (1951) (Japanese)

7) DOBREFF, N.: Klin. Wschr. 15, 1814 (1936)

8) Minamidani, M.: Folia pharmacol. jafion. 34, Procecdings 111 (1932)

9) Carlson, A.: Am.J. Physiol. 31, 151 (1912)

10) Takubo, Sh. and Morikawa, E.: Folia pharmacol. japon. 50, 433 (1954)

11) TAKUbO, SH.: Ibid. 52, 228 (1956)

12) TAKUbO, SH.: Ibid. 52, 238 (1956)

13) Takubo, Sh. AND UdaKa, H.: Shikoku Acta Medica 7, 204 (1955)

14) Takita, SH.: Arch. Klin. Chirur. 192, 383 (1939)

15) Ota, T. ANd Takubo, Sh.: Shikoku Acta Medica 5, 1 (1954)

16) MAGNUS, R.: Pflügers Arch. 102, 123 (1904)

17) KRESS, K.: Ibid. 109, 608 (1905)

18) Fröhlich, A. AND Pick, E.: Arch. exper. Path. Pharmak. 74, 107 (1913)

19) Trendelenburg, P.: Ibid. 81, 77 (1917)

20) Mine, M. : J. of Kyoto Prefectural Med. Coll. 30, 1083 (1940)

21) YAMAO, E. : Falia pharmacol. japon. 30, 37 (1940)

22) BRODIE, B. AND DIXON, W.: J. Physiol. 30, 476 (1904)

23) Baeitr, G. AND PICK, E.P.: Arch. exper, Path. Pharmak. 74, 65 (1913) 
24) Hunt, R. : Am.J. Physiol. 45, 197 (1918)

25) Burns, D.: Dtsch. Arch. Klin. Med. 131, 70 (1920)

26) MIYAKE, T.: Folia endocrinol. japon. 6, 602 (1930)

27) YAMAO, E. : Folia pharmacol. japon. 27, 250 (1939)

28) KiDANI, T. AND KORIYAMA, M. : Japan. J. of Gastro-enterology 48, No. 2-3, 28 (1950)

29) BeRNheiM, F.: Am.J. Physiol. 104, 433 (1933)

30) Dale, H. aND Richards, A.: J. Physiol. 63, 201 (1927)

31) Haktmann, M. AND ISLER, H.: Arch. exper. Path. Pharmat. 192, 141 (1939)

32) Meier, R. AND Müller, R. : Schweiz. Med. Wschr. 69, 1271 (1939)

33) El.LiOTT, T.: J. Physiol. 32, 401 (1905)

34) KLEE, P.: Minch. Med. Wschr. 61, 1044 (1914)

35) Watanabe, K.: Arch. Path. Anat. u. Physiol. 251, 494 (1924)

36) AKAZOME, T.: Igaku-kenkyu 3, 11 (1929) (Japanese)

37) KATAGI, F,: Folia pharmacol. japon. 38, 59 (1943)

38) KeEFER, G. AND BLoOMFieid, A.: Arch. Int. Med. 38, 303 (1926)

39) Tetelbaum, A.: Z. ges. exper. Med. 52, 408 (1926)

40) KellermanN, E.: Arch. Verdauungskrh. 45, 76 (1929)

41) VEACH, H. : J. Tharmacol. 61, 230 (1937)

42) TAKEUCHI, I.: Japan. J. of Gastro-enterology 49, No. 10, 1 (1952)

43) UEMURA, Y.: Ibid. 50, No. 1, 32 (1952) 